\title{
Testimonios y militancias de mujeres en Argentina: Revolución, Derechos Humanos y Feminismo
}

\section{Women's Testimonies and Militancy in Argentina: Revolution, Human Rights and Feminism}

\begin{abstract}
Resumen
En este artículo se recortará un momento específico de las trayectorias, tanto del testimonio como de la militancia de las mujeres, que han trazado recorridos muy poderosos y ciertamente variados en las últimas décadas en Argentina y en América Latina que se abre a inicios de la democracia, luego de la dictadura argentina (1976-1983), con los testimonios de las mujeres sobre los crímenes sexuales padecidos en centros clandestinos de detención (CCD). Forman parte de una segunda ola dentro de la tradición literaria y cultural del testimonio latinoamericano. En un primer movimiento el testimonio de matriz revolucionaria, que abarca al testimonio etnográfico, al guerrillero y al periodístico, fue institucionalizado en 1970 por Casa de las Américas bajo el modelo revolucionario que desde Cuba se extendía por el continente. Para abordar el corpus de testimonios de mujeres sobre el terrorismo sexual consideramos oportuno señalar la articulación de tres matrices que han permeado tanto los textos testimoniales como las prácticas políticas: el relato revolucionario, la narrativa humanitaria y el discurso feminista.
\end{abstract}

Palabras claves

Testimonio; militancia; narrativa humanitaria, feminismo; Argentina.

\begin{abstract}
In this article,will examine a specific moment in the trajectories of both women's testimony and militancy, which have traced very powerful and certainly varied paths in recent decades in Argentina and Latin America, beginning at the beginning of democracy, after the Argentine
\end{abstract}


dictatorship (1976-1983), with women's testimonies on the sexual crimes suffered in clandestine detention centers (CCD). They are part of a second wave within the literary and cultural tradition of Latin American testimony. In a first movement, the testimony of revolutionary matrix, which includes ethnographic, guerrilla and journalistic testimony, was institutionalized in 1970 by Casa de las Américas under the revolutionary model that spread throughout the continent from Cuba. In order to approach the corpus of women's testimonies on sexual terrorism, we consider it appropriate to point out the articulation of three matrixes that have permeated both testimonial texts and political practices: the revolutionary narrative, the humanitarian narrative and the feminist discourse.

Keywords

Testimony; Militancy; Humanitarian Narrative, Feminism; Argentina.

\section{Trayectos}

Las trayectorias tanto del testimonio como de la militancia de las mujeres han trazado recorridos muy poderosos y ciertamente variados en las últimas décadas en Argentina y en América Latina cuya riqueza resulta inabordable. En esta ocasión vamos a recortar un momento específico que se abre a inicios de la democracia, luego de la dictadura argentina (1976-1983), con los testimonios de las mujeres sobre los crímenes sexuales padecidos en centros clandestinos de detención (CCD). Forman parte de una segunda ola dentro de la tradición literaria y cultural del testimonio latinoamericano. En un primer movimiento el testimonio de matriz revolucionaria, que abarca al testimonio etnográfico, al guerrillero y al periodístico, fue institucionalizado en 1970 por Casa de las Américas bajo el modelo revolucionario que desde Cuba se extendía por el continente. Con los inicios de las transiciones a la democracia en el Cono Sur en la década de 1980 se inaugura un proceso de reinstitucionalización del testimonio (una segunda ola) bajo el paradigma de la narrativa de los derechos humanos. (Basile 2021) ${ }^{1}$

${ }^{1}$ En mi artículo "Reinstitucionalización del testimonio en América Latina desde la narrativa humanitaria" analizo extensamente esta tradición del testimonio latinoamericano marcando el pasaje entre el testimonio de matriz revolucionaria de la década de 1970 y el testimonio bajo la 
Para abordar el corpus de testimonios de mujeres sobre el terrorismo sexual consideramos oportuno señalar la articulación de tres matrices que han permeado tanto los textos testimoniales como las prácticas políticas: el relato revolucionario, la narrativa humanitaria y el discurso feminista. Resulta productivo describir un desarrollo temporal y diacrónico entre estas tres matrices, pero también una mirada sincrónica que revela los cruces, tensiones, discrepancias o confluencias entre ellas. Intentamos armar este itinerario marcando hitos en los cuales confluyen militancias y testimonios a partir de la publicación de cuatro libros de testimonios. Bajo el paradigma humanitario, es el testimonio mismo el instrumento de la militancia cuando este se esgrime en los juicios y luchas por la verdad, memoria y justicia. $\mathrm{Si}$ bien nuestro foco se centra en los testimonios y militancias de matriz humanitaria, se vuelve necesario comenzar con una breve aproximación al testimonio revolucionario previo para visualizar sus cambios y continuidades.

\section{El relato revolucionario}

Durante la década de los 70 una parte importante de la militancia de las mujeres en Argentina (y en América Latina) estaba en gran medida en el seno de las agrupaciones revolucionarias cuyas normas y valores entraban en conflicto con los movimientos feministas que, si bien dominaban algunos escenarios como el europeo y el estadounidense, también se estaban desarrollando en estos territorios. ¿Se trataba de dos corrientes excluyentes cuyas demandas divergían notablemente o podemos pensarlas como alternativas a través de las cuales las mujeres ocupaban escenarios de los varones con sus participaciones en el espacio público y en la política? ¿O tal vez la militancia y el feminismo convivían en una crispada tirantez en ciertos casos? Varios textos se han ocupado de examinar los testimonios de la militancia de las mujeres en la Argentina de los años 70. Quiero detenerme, sin

narrativa de los derechos humanos de la década del 1980, focalizando en el caso argentino (Basile "Reinstitucionalización”). 
embargo, en las tensiones entre la militancia revolucionaria y la del feminismo, las interferencias y discordancias, pero también en algunos modos en que estas dos tendencias se potenciaban.

En esta década la militancia feminista comienza a institucionalizarse en agrupaciones como la Unión Feminista Argentina (UFA) que se funda en 1970 y el Movimiento de Liberación Feminista creado en 1972, entre otras. Van a confrontar y dialogar con dos fuerzas, la militancia revolucionaria y el proceso modernizador.

Varios son los textos que explican los conflictos de los reclamos femeninos al interior de las agrupaciones de la izquierda radical. Alejandra Oberti en Las revolucionarias... (2015) analiza, a partir de una serie de testimonios de militantes, en especial de Montoneros y del PRT-ERP, el lugar de la mujer asignado en el interior de esas agrupaciones, así como los desplazamientos que ellas mismas fueron efectuando como efecto de sus participaciones. La paradoja parece atravesar las normas y conductas de estos movimientos. Por un lado, se proponían ir contra las estrecheces de la vida burguesa, contra el individualismo y la moral burguesa, contra la economía del capitalismo y el consumo, contra los intereses de la propiedad para refundar la sociedad desde la proyección del modelo del hombre nuevo guevarista o la construcción de la subjetividad revolucionaria. Ello implicaba revolucionar desde la política hasta la vida privada, crear nuevos valores, prácticas, costumbres (solidaridad, sacrificio, humildad, lucha contra las injusticias, entrega al ideal, etc.), transformar las estructuras sociales, las instituciones, la cultura y las subjetividades, entre otras cuestiones. Pero, por otro lado, estas organizaciones de la izquierda armada exhibían, tanto en su ideología como en la práctica, zonas conservadoras tales como las directivas respecto a la familia y a la sexualidad. Propugnaban la pareja monogámica, la maternidad y la crianza de los hijos por parte de las mujeres (aunque con una mayor colaboración de los varones), condenaban y castigaban la infidelidad dentro de la familia revolucionaria y se oponían a la revolución sexual a la que consideraban como una falsa revolución y una cosificación de las relaciones entre los sexos. 
De modo que las vigas maestras del patriarcado limitaban, entorpecían y obstaculizaban continuamente el desempeño de las mujeres en la lucha, estas solían ser representadas desde tópicos y figuras sexistas y sus quejas apuntan a los roles que sus compañeros de militancia les asignaban: criar y cuidar a los niños, garantizar la economía y el orden del hogar, y apoyar a los varones en sus luchas. Estas pautas evidencian la sujeción al modelo de domesticidad tradicional otorgado a la mujer, muy distante de las propuestas del feminismo. No siempre podían asistir a las reuniones partidarias porque debían cuidar a sus hijos, y fueron muy pocas las que llegaron a ocupar cargos de responsabilidad y lugares de conducción en las estructuras de las organizaciones guerrilleras.

En algunos casos eran percibidas como potenciales obstáculos para el varón militante debido a sus presupuestas tendencias burguesas, a su individualismo, a su atraso ideológico y su falta de conciencia de clase, capaces entonces de boicotear la militancia de sus parejas. En otros casos se las representaba como compañeras llenas de virtudes, hermosas, ágiles, serenas desde una visión estetizante de la joven guerrillera. En varias propuestas la defensa de los derechos de la mujer (en especial referida a las obreras) esgrimida desde estas agrupaciones se articulaba en términos de "ama de casa", de los derechos de los hijos a la salud, educación, alimento y de una mejora en los salarios.

No obstante, Oberti también señala los corrimientos que las mujeres fueron efectuando a medida que participaban activamente en la militancia, si bien sus acciones no lograron una transformación del patriarcado, sí supusieron una interpelación a las normas y valores de los varones al interior de las organizaciones de la izquierda revolucionaria y un empoderamiento de las mujeres como sujetos políticos, como fuerzas y agentes de la historia. Ellas marcan una fisura en la imagen tradicional que les era otorgada y logran desbordar los roles asignados a su género. La participación política implicó para las mujeres salir de los lugares tradicionalmente estipulados a lo femenino, actuar en el espacio público de una manera nueva, convertirse en un sujeto político y formar parte de las fuerzas de la historia que estaban transformando la sociedad, aunque sin correrse del todo de los 
límites del patriarcado: "En este marco, muchas sintieron la profunda convicción de que el discurso feminista no era necesario. Fue la subjetividad militante [...] la que vino a dar respuesta a los reclamos femeninos" (Oberti 180).

Catalina Trebisacce ("Una segunda lectura") también advierte la conflictiva recepción de las demandas feministas por parte de la militancia de izquierda del Partido Socialista de los Trabajadores (PST) y del Frente de Izquierda Popular (FIP), aun cuando en estos espacios hubo intentos más o menos orgánicos de incluir al feminismo, tales como el grupo de mujeres Muchacha del PST o del Movimiento Feminista Popular (MOFET) del FIP. En ambos casos la militancia de izquierda puso obstáculos y límites a su incorporación. Por su parte, para las feministas la lucha de clases no era el principal objetivo.

Pero además Trebisacce discute con las perspectivas analíticas que consideran al feminismo de los 70 como una expresión más del proceso de radicalización política y propone situarlo como una respuesta confrontativa a la renovación del modelo femenino de la "mujer moderna" que se estaba gestando en los medios de comunicación masiva. Revistas para la mujer o con secciones dedicadas a ellas, como Primera Plana, Claudia, Vosotras, Siete días, Para ti, o programas y propagandas televisivas invitaban a incluir a las mujeres en el proceso modernizador que se estaba generando desde mediados de los 60 en los grandes centros urbanos. Combatían a la mujer atrasada, que no se había liberado del trabajo doméstico, la invitaban a trabajar y a aggiornar sus conductas sexuales. Sin embargo, a los ojos de las feministas este modelo era ambiguo ya que, si por un lado instaban a las mujeres al cambio, a cuestionar sus pautas, al trabajo y a cierta liberalidad sexual, por otro lado, las conducían al consumo de productos modernos, desde los electrodomésticos que les facilitarían el trabajo de la casa hasta los productos de belleza para atraer a su esposo. Denuncian la "cosificación" de la mujer, sometida a la sociedad machista y de consumo. Es decir, en este modelo de la "mujer moderna" no había un cuestionamiento profundo del patriarcado. Las feministas intervenían en estos medios de comunicación para discutir modelos y afirmar sus puntos de vista, al mismo tiempo que desarrollaban otras prácticas 
propias en publicaciones como la revista Persona y volanteadas, y a partir de grupos de concientización en los que las mujeres expresaban y compartían sus experiencias para luego analizarlas.

Este panorama nos lleva a preguntarnos si esta ola del feminismo argentino constituyó un movimiento emergente que debió lidiar por un espacio propio en un contexto en parte colonizado por los medios de comunicación masiva y en parte protagonizado por la militancia revolucionaria. Un inicio en el que resultaba ciertamente difícil alcanzar visibilidad en la convulsionada década de los 70. Pero, por otro lado, la militancia en las organizaciones guerrilleras fue un canal en el que ciertamente las mujeres accedieron al espacio público a través de prácticas políticas, se empoderaron en su capacidad de lucha sumando estrategias que les servirían para actuar en nuevos escenarios con sus propias demandas. En esta línea se observan formas alternativas de militancia de las mujeres que no necesariamente pasan por el feminismo pero que coinciden en el acceso a roles de poder propios del varón.

\section{La narrativa humanitaria}

Hacia la década de los 80 asistimos a la apertura democrática en Argentina que colocó a los derechos humanos como dispositivo para leer el pasado reciente -al tiempo que la lucha revolucionaria ya no constituía una posibilidad política. En este contexto, el Presidente Raúl Alfonsín crea la CONADEP² que se ocupará de recopilar testimonios de las víctimas (cuyas declaraciones luego fueron publicadas en el Nunca Más en 1984), e impulsa los Juicios a las Juntas militares (1985), bajo el encuadre de la narrativa humanitaria. Las sobrevivientes ex

${ }^{2}$ La CONADEP (Comisión Nacional sobre la Desaparición de Personas) fue creada por el presidente argentino Raúl Alfonsín el 15 de diciembre de 1983 con el objetivo de investigar las reiteradas y planificadas violaciones a los derechos humanos ocurridas durante la dictadura (19761983) y funcionó entre 1983 y 1984 recopilando testimonios de sobrevivientes, familiares de víctimas y testigos casuales, y visitando centros clandestinos de detención. 
militantes, en muchos casos, aceptaron testimoniar en estos dos espacios, aunque en un primer momento no les resultó sencillo pasar del discurso político de tono revolucionario usado en la militancia hacia el lenguaje de los derechos humanos, pero debieron hacerlo para poder radicar las denuncias en diversos foros que requerían ese formato de discurso. ¿Cómo aparecen los testimonios de mujeres en este primer modelo del testimonio en clave humanitaria del Nunca Más?

El propósito de la CONADEP estuvo dirigido a revelar la maquinaria del terrorismo de Estado y a juntar pruebas para el Juicio a las Juntas. Bajo estas directivas, los testimonios refirieron el ciclo de la desaparición de personas (allanamiento de las propiedades, secuestro de personas, ingreso y cautiverio en centros clandestinos, aniquilación a través de fusilamientos, las incineraciones o los vuelos de la muerte, la inhumación de los cadáveres como NN, etc.). Dieron cuenta de la existencia, la estructura y el funcionamiento de gran cantidad de Centros clandestinos de detención (CCD) a través de descripciones, de dibujos de planos y de la inspección in situ de los mismos con la concurrencia de sobrevivientes, arquitectos y fotógrafos. Permitieron la elaboración de listas de desaparecidos y de perpetradores, explicaron los métodos de coerción física y psíquica, el funcionamiento de los grupos de tareas, el saqueo de propiedades, la apropiación de niños, entre otras prácticas cuya magnitud, carácter sistemático, clandestino y de alcance nacional fueron determinados. Los datos aportados por los testimonios y pasados por diversos métodos de validación (con la colaboración de antropólogos forenses, abogados, fotógrafos, arquitectos, con el uso de tecnología de vanguardia y sistemas de computación, con el aporte de datos provenientes de fuentes militares, de análisis genéticos, entre otros) construyeron la referencia y certificaron la verdad (no olvidemos que la CONADEP es una "comisión de verdad") en gran medida invisible o conocida parcialmente hasta el momento debido la clandestinidad del operar de las fuerzas represivas y luego a la destrucción de las pruebas y encubrimiento de información - tal como desarrolla Emilio Crenzel en su imprescindible estudio La historia política del Nunca Más: la memoria de las desapariciones en la Argentina (2008)—. 
La matiz humanitaria también interviene en la configuración narrativa del testimonio y en la representación de sus actores ya que postula el carácter de víctima inocente que ha padecido la violación a sus derechos humanos, y que es descripta esquivando su militancia en la izquierda revolucionaria, sus ideales y proyectos, evitando historizar las causas del crimen, sustituyendo el argumento político por el imperativo moral, desplazando la matriz de la lucha de clases o la antinomia entre el pueblo y la oligarquía por el enfrentamiento entre víctimas y victimarios, y corriéndose así de los argumentos políticos esgrimidos por las Fuerzas Armadas para justificar su accionar. Este vaciamiento histórico-político es colmado por una “descripción fáctica y en detalle de los secuestros, las torturas padecidas, las características de los lugares de cautiverio, la precisión de los nombres de los cautivos y de los responsables de las violaciones", que se reorganiza por centro clandestino a partir de un total aproximado de 379 testimonios seleccionados (Crenzel "La historia política" 44-45, Basile "Aproximaciones").

Crenzel describe el debate en torno al modo de escribir el Nunca Más entre una escritura en clave política finalmente desechada y otra en el marco de la narrativa humanitaria que terminó por elegirse. Sus objetivos debían ser dar cuenta de una condena moral a la dictadura y a las violaciones a los derechos humanos, y convertirse en un legado para el futuro. Asimismo, se propuso que predominara un estilo vívido y objetivo, despojado de adjetivos y carente de tecnicismos, de amplia lectura para todos los públicos, con abundantes testimonios, descripciones, datos y fotografías que certificaran convincentemente lo ocurrido ante los posibles incrédulos, y con el protagonismo de los sobrevivientes y familiares. Todo lo cual condujo a describir la secuencia del secuestro, la tortura y la desaparición. Como vemos la matriz humanitaria también condicionó la escritura del Nunca Más. (Crenzel 91-98, Basile “Aproximaciones”).

Estos testimonios forjan una primera representación acabada del modo inédito de represión ejercida por los militares, configuran un primer imaginario del terrorismo de Estado con sus actores, espacios y metodologías. Inauguran un código lingüístico: en tomo a la palabra desaparecido se abre un abanico de nuevas 
significaciones ("chupadero", "centro clandestino de detención", "traslado", "submarino", "pozo", "grupo de tareas", "capucha", "parrilla", "máquina", etc.). Los testimonios crean un nuevo tipo de relato que sigue el siguiente itinerario: secuestro/desaparición; centro clandestino de detención/torturas; muerte/desaparición del cadáver (Basile). Instauran, al decir de Crenzel, un "régimen de memoria" dador de claves interpretativas y de estilos narrativos para evocar, pensar y transmitir los sentidos del pasado reciente.

Es en este espacio que la militancia feminista se encuentra, enfrenta y vincula en la década de los 80 , entre otras instituciones y fuerzas políticas, con la militancia de las mujeres en organismos de derechos humanos (que es el cruce que aquí nos interesa), mientras en los 70, como vimos, el feminismo debía defender y construir un espacio propio frente a la militancia de las mujeres en la izquierda revolucionaria y ante la proyección de los modelos femeninos de la mujer moderna por parte de los medios de comunicación masiva. El surgimiento de las Madres de Plaza de Mayo (1977) y su protagonismo a partir de los 80 junto con las Abuelas de Plaza de Mayo (1977) fue, sin lugar a duda, una militancia de las mujeres de enorme importancia a nivel nacional e internacional. Se constituyó en un referente difícilmente soslayable para las feministas.

Mónica Tarducci (2020) recorre los vínculos de ciertas agrupaciones feministas con las Madres, así como la presencia y colaboración de las Madres con actividades organizadas por las feministas. Señala al grupo feminista ATEM (Asociación de Trabajo y Estudio de la Mujer) fundado en 1982 como el primero en relacionar la violencia política con violencia sexual e interesarse por las organizaciones de Madres, Abuelas de Plaza de Mayo y Familiares de detenidosdesaparecidos. Consideraron la violencia contra las mujeres como una cuestión de derechos humanos, investigaron la situación de las mujeres militantes en cautiverio y bajo tortura, así como implementaron la perspectiva del género para enfocar a las mujeres desaparecidas. Las Jornadas que ATEM organizaba constituyeron uno de los espacios de intercambio en donde se expusieron los vínculos entre feminismo y 
derechos humanos, ${ }^{3}$ allí se resolvió la adhesión a los reclamos de las Madres (referidas a la "aparición con vida de los detenidos-desaparecidos, recuperación de los niños secuestrados, repudio a la ley de autoamnistía y castigo a los responsables") y se contó con la presencia de ex detenidas-desaparecidas, como Ana María Careaga que en 1983 testimonió su experiencia concentracionaria, y de algunas Madres comprometidas en ciertas actividades de ATEM.

También la Multisectorial de la Mujer, formada mayoritariamente por partidos políticos, pero donde las feministas demandaban insistentemente por sus derechos, tuvo una mirada atenta sobre los Derechos Humanos. Entre otros ejemplos, la Multisectorial realizó el 9 de abril de 1984 un homenaje a las Abuelas, Madres y Familiares de detenidos y desaparecidos, apoyó los reclamos de las Madres sobre la "aparición con vida y la restitución de los niños a sus familias legítimas" y advirtió sobre las violaciones y vejámenes sexuales cometidos contra las detenidas-desaparecidas.

Finalmente, la mirada feminista sobre la represión política logró imponerse después de años gracias a la labor incansable de, por ejemplo, las mujeres de CLADEM (Comité de Latinoamérica y el Caribe para la Defensa de los Derechos de la Mujer $)^{4}$ que presentaron en 2010 un amicus curiae en la causa 4012, "Riveros, Santiago Omar y otros", sobre crímenes de lesa humanidad cometidos durante la última dictadura. El objetivo de esa presentación era que en los juicios por los crímenes de lesa humanidad cometidos en el marco de la represión ilegal se

${ }^{3}$ Entre otros ejemplos, Tarducci (2020) recuerda "Por ejemplo, en 1983 se presentó la ponencia "Una perspectiva feminista frente a los Derechos Humanos" de Magui Bellotti y Nélida Koifman [...] En las Jornadas de ATEM, de 1984, en el panel "Las mujeres y los Derechos Humanos", expusieron Madres, Abuelas y Familiares, y Alicia Lombardi, que formaba parte de ATEM, presentó el trabajo "Las Madres de Plaza de Mayo, un enfoque feminista". En otro panel, "Psicoterapia y represión política", expusieron Marta L’Hoste y Raquel Bozzolo, del Equipo de Asistencia Psicológica de Madres de Plaza de Mayo y Florinda Hara y Rosa Maciel del Movimiento Solidario de Salud Mental, organización vinculada a Familiares de Desaparecidos y Detenidos por Razones Políticas".

${ }^{4}$ Entre los objetivos de CLADEM (fundada en 1987 en San José, Costa Rica) figura la defensa y exigencia de los derechos humanos de las mujeres en la región desde una visión feminista. Desde esta perspectiva, promueve la justicia social y los derechos económicos, sociales y culturales de las mujeres y sus derechos sexuales y reproductivos. 
juzgaran los delitos contra la integridad sexual de hombres y mujeres mantenidos en cautiverio como delitos de lesa humanidad —afirma Tarducci.

Pero también son conocidas las disidencias de María Elena Oddone, una reconocida líder de la militancia feminista, fundadora del Movimiento de Liberación Femenina-MLF en 1972 y directora de la revista Persona, con las Madres de Plaza de Mayo. Oddone logró mantener al MLF por fuera de las tensiones de la política nacional durante los 70, pero en los inicios de los 80 (ahora bajo el nombre de Organización Feminista Argentina-OFA) comenzó a enfrentarse con nuevos grupos feministas de izquierda. Lo que dio lugar a una radicalización de la OFA en oposición a estos nuevos grupos, visible en las discutidas y criticadas intervenciones de Oddone que provocaron el descontento de varias feministas, tal como explica Catalina Trebisacce ("Problemas en la reconstrucción").

La carta escrita por María Elena Oddone en relación con las Madres de Plaza de Mayo en septiembre de 1985 constituyó la piedra del escándalo, ya que allí la líder feminista se niega a adherirse públicamente a las Madres de Plaza de Mayo ya que no encuentra puntos de coincidencia con ellas y considera que ese vínculo significaría un desdibujamiento de los objetivos feministas. Además, su postura termina por apoyar la teoría de los dos demonios al equiparar las prácticas de los militantes revolucionarios con las de las fuerzas armadas. El repudio a estas afirmaciones condujo a la expulsión de María Elena (Trebisacce "Problemas en la reconstrucción"; Tarducci).

Es en el escenario de estos vínculos y controversias, que un grupo de mujeres sobrevivientes va a introducir -desde el espacio de las luchas por la memoria, verdad y justicia- el dispositivo del género para leer el pasado reciente, va a interpelar la figura sexualmente neutra de la víctima, va a señalar la violencia política sexuada padecida en los Centros clandestinos de detención y en las cárceles, va a cruzar el relato humanitario con una perspectiva de género, como un modo de interferirlo y a la vez potenciarlo. "Es necesario hacer visible el impacto diferenciado de la violencia represiva sobre mujeres y varones, y repensar las políticas de memoria y de derechos humanos con perspectiva de género", sostienen 
María Sonderéguer y Violeta Correa (291). Sin embargo, este giro se fue desarrollando a lo largo de unas cuatro décadas.

Varias son las periodizaciones en torno al testimonio de la historia reciente en Argentina, pero aquí voy a recuperar el itinerario que traza Paula Simón ya que organiza el corpus testimonial producido por mujeres ex detenidas-desaparecidas en las cárceles y en los CCD. Considera tres trayectos. El primero se extiende desde la finalización de la dictadura hasta mediados de los 90. Son en su mayoría testimonios masculinos, mientras las voces femeninas surgen de manera pujante en el exilio. El segundo periodo va desde mediados de los 90 hasta el 2003, año clave en que se anulan las llamadas Leyes de la Impunidad y la reactivación de los juicios provocaron un florecimiento editorial de testimonios femeninos que incidieron en las luchas por la reivindicación de las víctimas. De 2003 al 2015 se extiende el tercer trayecto caracterizado por la alta exposición de los testigos dada por la reactivación de los juicios y la apertura de espacios públicos de la memoria (Simón 2019)..$^{5}$

\footnotetext{
${ }^{5}$ Simón configura un corpus para cada etapa. Dentro del primer trayecto (1983-1998) coloca: Preso sin nombre, celda sin número (1982), de Jacobo Timerman; Recuerdo de la muerte (1984) de Miguel Bonasso; Prisionero político. Testimonio sobre las cárceles políticas argentinas (1984), de Carlos Zamorano; Sobrevivientes de La Perla (1984), de Gustavo y Patricia Contemponi; Con mis hijos en las cárceles del Proceso (1985), de Luis José Bondone; La Perla (1986), de Roberto Reyna, y Cuerpo I - Zona IV (El infierno de Suárez Mason) (1988), de Blanca Buda. Ante el predominio de voces masculinas, es en el exilio donde encontramos varias voces femeninas en este primer momento: The Little School. Tales of Disappearance \& Survival in Argentina (1986) de Alicia Partnoy y You can 't drown the fire (1988) de la misma autora; Pasos bajo el agua (1987) de Alicia Kozameh; Una sola muerte numerosa (1997) de Nora Strejilevich, y Una versión de mi misma también de Nora Strejilevich (no fue publicada). En la segunda etapa (1998-2003) encontramos: Poder y desaparición. Los campos de concentración en Argentina (1998) de Pilar Calveiro; Redes de la memoria (2000) de Jorge Boccanera (comp.); Sueños sobrevivientes de una montonera (2000) de Susana Jorgelina Ramus y Ese infierno. Conversaciones de cinco mujeres sobrevivientes de la ESMA (2001) de Munú Actis, Cristina Aldini, Liliana Gardella, Miriam Lewin y Elisa Tokar. En el tercer momento (2003-2014) contamos con el siguiente corpus: reediciones en Argentina de Una sola muerte numerosa (2006) de Nora Strejilevich, La Escuelita. Relatos testimoniales (2011) de Alicia Partnoy, Pasos bajo el agua (2006) de Alicia Kozameh, y las publicaciones de El arte de no olvidar. Literatura testimonial en Chile, Argentina y Uruguay entre los 80 y 90 (2006) de Nora Strejilevich; Nosotras, presas políticas: obra colectiva de 112 prisioneras politicas entre 1974 y 1983 (2006) de varias autoras; Putas y guerrilleras (2014) de Miriam Lewin y Olga Wornat, y Diálogos de amor contra el silencio (2006) de María del Carmen Sillato.
} 
Considerando estas etapas del testimonio femenino he seleccionados tres volúmenes de testimonios para ilustrar los cambios en el itinerario que voy a trazar: las publicaciones del Nunca Más (1984), de Ese infierno. Conversaciones de cinco mujeres sobrevivientes de la ESMA (2001) de Munú Actis, Cristina Aldini, Liliana Gardella, Miriam Lewin y Elisa Tokar cuya segunda edición data de 2006, y Putas y guerrilleras (2014) de Miriam Lewin y Olga Wornat. En cada caso establezco un vínculo con el avance de los juicios y la legislación, y recupero los cambios de contexto. Quiero aclarar que respecto a la primera etapa caracterizada por la emergencia de testimonios de mujeres en el exilio que Simón ha señalado, he preferido abordar el Nunca Más publicado en Argentina ya que allí se fragua con claridad lo no dicho en los testimonios respecto al género, la laguna ya no de lo indecible que Agamben observó como el centro de todo testimonio, sino la laguna de las instituciones judiciales, culturales y políticas que no estaban preparadas para oír y procesar la perspectiva de la violencia sexual. Ese testimonio de las mujeres configura una suerte de grado cero que luego irá sumando capas para construir el complejo edificio del testimonio sobre el terrorismo sexual.

\section{1. El grado cero del testimonio sobre la violencia sexual: el Nunca Más}

Volvamos a la pregunta inicial sobre la índole de los testimonios de mujeres en clave de género, publicados en el Nunca Más, es decir aquellos que focalizan en los padecimientos debidos a su condición femenina, en especial las violaciones y vejaciones de índole sexual que podemos leer en las páginas 49-52, 67, 155, 191, 211 y 317 (Crenzel 236). En varias de estas denuncias, los abusos sexuales, las violaciones, los manoseos y vejaciones sufridas en los Centros Clandestinos de Detención se incluyen en el apartado "Torturas" junto a una larga lista de padecimientos físicos y psíquicos como la picana eléctrica, el apaleamiento, las quemaduras, estiramientos, colgamientos, despellejamiento, el submarino seco y mojado, los simulacros de fusilamiento, el enterramiento, los insultos y las 
amenazas con los familiares, entre otros. Esta inclusión obtura el reconocimiento de la especificidad de los crímenes sexuales atravesados por el género.

Tampoco hay un reconocimiento de las mujeres (y varones) como un grupo individualizado dentro de las víctimas, salvo el caso de las embarazadas bajo el rótulo de "Niños desaparecidos y embarazadas", que permita visualizar en el Nunca Más un proceso de clasificación de las víctimas que atienda al género, ni que de cuenta de las victimizaciones que los represores efectuaban en ese sentido. ${ }^{6}$ Además, en las declaraciones sobre violaciones los nombres y apellidos de las víctimas son sustituidos por iniciales para conservar el anonimato y preservar la intimidad.

Estas características en el modo de consignar los delitos sexuales se debían a que estos se consideraban "una forma más de tormentos", sin individualizar su especificidad. Ello implicaba que las violaciones estaban subsumidas en el grupo más amplio de las torturas ya que eran crímenes de menor gravedad. Por otro lado, se los percibía como una "afrenta al honor privado" y por ello solo podían investigarse si medía la voluntad de la víctima ya que el proceso penal podía suponer una nueva vejación e intromisión en la intimidad, de allí la preservación de la identidad tras el anonimato. De modo que, si la mujer no declaraba, el agresor quedaba impune. Por su parte, en los Juicios a las Juntas, se les permitía hablar de las vejaciones sexuales padecidas pero esta información no era útil para la construcción de las pruebas, por ello a veces los jueces las cambiaban de tema.

Lorena Balardini, Ana Oberlin y Laura Sobredo (2011) exploran el complejo recorrido legal de estos crímenes consignando fundamentalmente dos momentos. En esta primera instancia, protagonizada por la CONADEP, el Nunca Más y el Juicio a las Juntas, la justicia se centró en la necesidad de conceptualizar jurídicamente la noción de "desaparición" y de probar la existencia de un plan sistemático de represión a través de los testimonios. En este marco, las violaciones

${ }^{6}$ El Capítulo II "VICTIMAS" del Nunca Más configura la siguiente clasificación: "Niños desaparecidos y mujeres embarazadas", "Adolescentes", "La familia como víctima", "La represión no respetó inválidos ni lisiados", "Religiosos", "Conscriptos", "Desaparición de periodistas" y "Gremialistas". 
se minimizaban y hasta las mismas víctimas veían los crímenes sexuales como algo secundario. No se juzgaron ni los delitos "contra la integridad sexual" ni la “apropiación de niños". El "delito contra la honestidad" consignado por el Código Penal desplazaba la agresión contra la mujer hacia el varón (padre o marido) y hacia la sociedad que se veía amenazada en su moral. No existía ni desde la teoría de género ni desde lo jurídico una escucha diferenciada y una base legal para encuadrar estos testimonios. Ante esta falta de contención y frente a un contexto donde las violaciones eran fuertes motivos de tabúes, de condenas, vergüenza y culpa, muchas víctimas prefirieron no declarar o hacerlo de modo anónimo.

Claudia Bacci (2020) ilustra la compleja trama en que las declaraciones sobre violencia sexual se insertaban: por un lado, las tensiones entre la voluntad de testimoniar y el derecho al cuidado de la integridad subjetiva de la víctima y del entorno familiar, y por el otro los cortocircuitos en la posibilidad de la escucha por parte de las diferentes generaciones. Aborda el caso de Alicia Carminati, una joven que a los 23 años fue secuestrada junto a su padre y sometida a abusos sexuales. Su padre nunca pudo reconocer ni testimoniar el costado sexual de las violaciones a los derechos humanos padecidas por su hija.

Un segundo momento se abre, para las tres autoras antes mencionadas, con los Juicios por la Verdad (1998) en los que las sobrevivientes comienzan a dar cuenta de sus propias historias y no tanto de la desaparición de sus compañeros, poniendo el acento en la vivencia personal, en cuyo interior aparecían con mayor frecuencia los vejámenes vinculados al género. A ello se sumó un importante impulso que advino con las reformas en la legislación penal en relación con los delitos sexuales, tanto a nivel internacional —el reconocimiento de la violación como delito de grave infracción, delito de lesa humanidad y crimen de guerracomo local — la sustitución en 1999 del delito contra la honestidad por el delito 
contra la integridad sexual — en especial durante la década de los 90, tal como más adelante comentaremos (Balardini, Oberlin y Sobredo, 2011). ${ }^{7}$

Las embarazadas constituyen un caso aparte dentro de las mujeres detenidas desaparecidas también sacudido fuertemente por las cuestiones de género. En algunos casos sus vidas eran preservadas hasta el momento del parto para apropiarse de sus hijos y luego asesinarlas y en otros eran salvajemente violadas como en el CCD El Vesubio (Lewin y Wornat 117)

Este segundo plano de los delitos sexuales se acentuaba aún más debido a las características general de los testimonios volcado en el Nunca Más. Se procuraba, como adelantamos, un tono descriptivo y objetivo, sin demasiadas expresiones subjetivas, que evitara caer en una "enciclopedia del horror" (26), que se alejara del show del horror que la prensa había montado en los primeros meses de 1984 para mostrar los hallazgos de fosas comunes y los desentierros de presuntos desaparecidos (Feld). ${ }^{8}$ En el Nunca Más se proyecta, entonces, un primer modelo del testimonio de mujeres desde la narrativa humanitaria: un testimonio anónimo, de carácter privado, despersonalizado, objetivo, apolítico, decoroso y pudorosos, desplazado de su especificidad y subsumido en la tortura, que invisibiliza el delito sexual como un crimen contra los derechos humanos, y que exhibe los límites de la CONADEP, los organismos de derechos humanos y la justicia para considerarlos y juzgarlos. Constituye un grado cero del testimonio sobre delitos sexuales que significa por lo que no dice, por lo que resguarda, por lo que omite o minimiza, pero también porque deja entrever los desafíos que las víctimas deberán enfrentar

${ }^{7}$ Véase el análisis pormenorizado sobre las diversas y complejas reformas legales que Balardini, Oberlin y Sobredo detallan en el citado artículo y que en esta ocasión apenas mencionamos brevemente (2011).

${ }^{8}$ Durante los primeros meses de 1984, varios diarios argentinos se ocuparon cotidianamente de publicar noticias sobre las exhumaciones de cadáveres, que eran ordenadas por las denuncias judiciales bajo la presunción de que se trataba de inhumaciones clandestinas de desaparecidos llevadas a cabo durante la dictadura. Estas noticias focalizaban en los cadáveres referidos anónimamente como NN, mostraban con abundantes fotografías las aperturas de tumbas en cementerios, el hallazgo de fosas anónimas, la presencia de cráneos, huesos, prendas personales, de cuerpos atados, torturados, con alambres de púa, orificios de bala, con un tono escandaloso, sensacionalista, redundante, macabro e hiperrealista. Toda esta movida estaba en sintonía con el "destape mediático" desatado en la prensa que ahora se encontraba liberada de la censura de los militares (Feld). 
para lograr el reconocimiento de la implementación de un terrorismo sexual por parte del Estado.

\section{2. Experiencia e intimidad de las mujeres en Ese infierno...}

Coincidiendo con las periodizaciones antes mencionadas de Simón (2019) y de Balardini, Oberlin y Sobredo (2011), diversos autores hablan de un segundo momento considerado como un "boom de la memoria" (Lvovich y Bisquert; Amado) que se inicia hacia 1995, luego del periodo de impunidad inaugurado con las sanciones de las leyes de Punto Final (1986) y de Obediencia Debida (1987) y los indultos a los excomandantes (1990) que habían clausurado la vía judicial. Es un momento crucial de reactivación de la memoria por parte de los organismos de derechos humanos y de los familiares para enfrentar la impunidad del gobierno de Carlos Menem. Este nuevo impulso de las luchas por la memoria, verdad y justicia estaría dado por la confluencia de varios factores que detallamos a continuación. La presencia de las voces de algunos represores (como las confesiones, al periodista Horacio Verbitsky, del ex capitán de corbeta Adolfo Scilingo, que fueron dadas a conocer en El vuelo en 1995). Las publicaciones de relatos y testimonios de los setenta, en que retoman la palabra numerosas voces de ex militantes de las organizaciones revolucionarias de aquel pasado, volviendo sobre la experiencia de la militancia (lo que se advierte en los tres tomos que, desde 1997 y bajo el título de La voluntad, fueron compilados por Eduardo Anguita y Martín Caparrós). El surgimiento de la red nacional de las agrupaciones de H.I.J.O.S., que introduce una nueva voz en las políticas de la memoria. La conmemoración del vigésimo aniversario del golpe en 1996, que desplegó varias actividades e inundó la escena pública, y la creación de instituciones, monumentos, archivos y sitios de memoria

que fue penetrando en la sociedad. Además, poco a poco, la justicia fue avanzando por otros carriles, tales como los denominados "Juicios por la Verdad" (1998), el inicio de las causas sobre los robos de bebés (1997) y el juzgamiento de militares 
argentinos en tribunales internacionales como los de España, Francia e Italia (Salvi 53-64).

Me interesa detenerme en las causas sobre el robo de bebés ya que este acontecimiento judicial es el que en gran medida sostiene la escritura de Ese infierno. Conversaciones de cinco mujeres sobrevivientes de la ESMA (2001) de Munú Actis, Cristina Aldini, Liliana Gardella, Miriam Lewin y Elisa Tokar. En 1997 Abuelas de Plaza de Mayo inició una causa penal sosteniendo que el robo y la apropiación de bebés era parte de un plan sistemático impulsado desde el más alto nivel del Estado durante la dictadura. Los casos de robo de bebés y niños durante la dictadura habían quedado fuera del alcance las leyes de Punto Final y Obediencia Debida, por lo que la estrategia consistió en aprovechar este resquicio legal para poder juzgar a los represores. A partir de esta causa fueron detenidos Jorge Rafael Videla, Emilio Eduardo Massera y Jorge Eduardo "Tigre" Acosta, entre otros perpetradores. En 1998, el subcomisario Samuel Cobani Miara fue condenado a doce años de prisión por la apropiación ilegal de los mellizos Gonzalo y Matías Reggiardo Tolosa, hijos de Juan Reggiardo y María Rosa Tolosa, desaparecidos en 1977. Este inicio se completó años más tarde con el juicio oral y público por el Plan sistemático de apropiación de menores realizado en 2011-2012.

Las autoras de Ese infierno... —cuya primera edición data de 2001— sitúan el origen de las reuniones y conversaciones, que serán el punto inicial del armado del libro donde darán cuenta de sus experiencias como detenidas desaparecidas en la ESMA, en 1998, cuando ellas mismas colaboran como testigos en los juicios por la apropiación de recién nacidos. El primer modelo de los testimonios femeninos de matriz humanitaria, aquel que fue volcado en el Nunca Más, exhibía un tono neutral, objetivo, parco que evitaba el regodeo sensacionalista en el horror, y apuntaba a lo factual bajo la voluntad de conocer lo sucedido y juntar pruebas para el juicio soslayando las marcas personales de la testigo, sus opiniones y sentimientos. ¿Qué aporte ofrece este volumen testimonial? ¿Cuál es su nueva perspectiva? 
Ese infierno... introduce la experiencia cotidiana del centro clandestino de la ESMA, el día a día con los castigos, torturas y "traslados", las salidas para señalar a compañeros ("lancheos"), para ir a visitar a sus familiares, para cenar en algún restaurante o pasar el día en una quinta, la circulación de afectos y amores entre los detenidos pero también de resquemores y desconfianza, las comidas, los espacios, los trabajos asignados, las distinciones entre los detenidos, los diversos rangos, perfiles y personalidades de los represores, las diferentes etapas y cambios surgidos a lo largo del tiempo. Este volumen incursiona en la intimidad de las y los detenidos, en los sentimientos, opiniones, reflexiones, reacciones ante la violencia, muestra el laberinto de vínculos entre las detenidas y los represores con sus contradicciones, sus sombras y oscilaciones. Estas voces se detienen en las estrategias para sobrevivir dentro de la ESMA, los diversos trabajos que les eran asignados, el proyecto político del Almirante Emilio Massera, y las simulaciones de "recuperación".

Ello supone el abandono de la neutralidad y objetividad del testigo, y la emergencia y despliegue de estas subjetividades femeninas, es una incursión que va más allá de la descripción de lo factual, del delito que sirva de prueba, para narrar la cotidianeidad. Hay una complejización del tono asertivo, de la exclusiva denuncia que se enfoca en acusar, para explorar las zonas grises sin por ello dejar de condenar con fuerza. La conversación que se desarrolla entre estas cinco mujeres (reunidas a lo largo de tres años y medio) no procura arribar a conclusiones sobre cada discusión, no oculta las diferencias de opiniones respecto a los temas tratados, sino que expone los diversos puntos de vista. Es un texto coral de quienes se reconocen como "hermanas" (27), una obra abierta al lector que apuesta al valor de la conversación ("hicimos culto del afecto y la tolerancia" 30) y la riqueza del intercambio, aunque no se soslaya la condena final a la barbarie vivida en "ese infierno". En síntesis, aquí emerge todo aquello que no se dice en los juicios porque no añade elementos a las pruebas, por ello aparecen los grises que eran poco convenientes al necesario rigor del juicio. Se trata de "salir del amparo del lenguaje estructurado, del testimonio presentado ante un juez o un organismo de derechos 
humanos" (19) para poder contar "otro tipo de historias, no contadas todavía" (28). Articulan una mirada de adentro a cargo de quienes experimentaron en sus propias personas la violencia estatal.

Resulta interesante el cruce en estos testimonios de relatos en clave política (algo que no estaba en los testimonios del Nunca Más, dominados por la figura de la víctima inocente) y otros en clave de derechos humanos. Sin embargo, es indispensable marcar la siguiente evaluación. El relato revolucionario está colocado en el pasado como una etapa clausurada, y fuertemente atravesado por el sentimiento de derrota, de disgregación de la militancia y desarticulación de la estructura de la guerrilla a partir del golpe de 1976, de persecución, acecho, temor, soledad, desamparo y abandono por parte de la cúpula de las organizaciones en las que militaban. Con malas condiciones de seguridad y con escasísimas posibilidades de optar por el exilio, ya no era "esa experiencia plena, semejante a la felicidad, que a todos nos había embargado" (33) y "cuando caímos ya teníamos una moral de derrota" (45). Pero a su vez, ese pasado revolucionario centrado en un gran proyecto de transformación social, en una razón emancipatoria fuertemente dotada de un sentido utópico, en una solidaridad entre sus miembros dispuestos a dar la vida marcó a fuego las subjetividades de las autoras. ¿Cómo rehacer una vida luego de la derrota de estos grandes relatos revolucionarios, de la pérdida de esa vida sacudida por el fragor de la lucha y los actos heroicos, del fin del "entusiasmo" y de esa "intensidad" de amor por una sociedad más justa? Ellas describen las dificultades para encontrar valor a sus actividades una vez que salieron de la ESMA y en esta línea la participación en los juicios contra los genocidas como testigos es una vía que les devuelve sentido a sus vidas.

Si la revolución quedó en el pasado, en cambio la matriz de los derechos humanos es la que atraviesa la existencia de ellas en el presente, es la que vehiculiza las declaraciones de sus testimonios en la justicia a propósito de las causas por el robo de bebés, es la motivación que las lleva a reunirse y armar este libro y es la que lanza la necesidad de una segunda edición (2006) cuando Néstor Kirchner abre la ESMA y la inaugura como sitio de memoria en 2004 e inicia un nuevo ciclo en 
las luchas por la memoria, verdad y justicia. De modo que el impulso humanitario se despliega desde el presente hacia el futuro: "Quisiéramos que parte de la ex ESMA [...] se transforme en un espacio para promoverlos [los Derechos Humanos] y celebrarlo: un espacio para la vida. Creemos que los desaparecidos hubieran estado de acuerdo" (303).

Otro de los elementos decisivos de este volumen es que da cuenta de la construcción del testigo femenino, del trabajo emprendido durante años (y décadas en algunos casos) para decidirse y poder testimoniar: "nos costó veinte años reunirnos" (13). En esta línea algunas de ellas exponen los obstáculos, las dificultades para testimoniar al inicio de la democracia ante la CONADEP y en los Juicios a las Juntas. Hay toda una reflexión en torno a la configuración subjetiva del testigo, a la conformación de una disposición íntima, a la existencia de una escucha por parte de los jueces y de la sociedad que debe lograrse para poder testimoniar aquello que "durante mucho tiempo juzgamos intransmisible" (19). Debían quitarse la culpa por haber sobrevivido y escapar al estigma de la sobreviviente como traidora, sospechada de colaboración (Longoni), tenían que volverse "dignas", ahuyentar el miedo a las represalias de los represores, controlar la reemergencia del dolor de la herida abierta. Fue a partir de 1998 con los juicios por la apropiación de menores, que condenaron y llevaron a la cárcel nuevamente a los genocidas, que "sentimos la necesidad de hablar" (19) ya que "nuestros tiempos internos solo coinciden ahora entre sí y con el tiempo social" (20). Se trata de la asunción de la militancia por los DD.HH. a través del rol de testigos que ellas asumen en estos juicios sobre la apropiación de bebés. Testimonio y militancia confluyen en este volumen y dan cuenta del acto de testimoniar como uno de los modos privilegiados de la militancia por los derechos humanos.

Finalmente nos preguntamos por el modo en que se introduce el dispositivo del género en estos testimonios. En primer lugar, este texto reúne solo voces de mujeres: "Resolvimos ser solo mujeres en el grupo porque para nosotras haber pasado por el campo tuvo tintes especiales vinculados con el género: la desnudez, el ultraje a la intimidad, las vejaciones, el acoso sexual de los represores, nuestra 
relación con las compañeras embarazadas y sus hijos" (28). En sus palabras comienza a delinearse el lugar particular que ocupaban las mujeres dentro de la ESMA. Por un lado, denuncian la violencia política sexuada que abarca los manoseos, la desnudez obligada en las duchas, las ofensas a sus cuerpos, las revisiones ginecológicas, las violaciones, entre otros modos. En varias oportunidades solían responder ocultando su cuerpo y borrando su femineidad. El caso de las embarazadas ocupa un lugar significativo ya que además de que algunas de las autoras las acompañaron y compartieron los nacimientos, están en juego sus testimonios en las causas por apropiación de los bebés y la denuncia de las maternidades clandestinas que, como adelantamos, constituye el incipit de este volumen.

Sus testimonios describen el complejo universo de vínculos entre víctimas y victimarios dentro de la ESMA (que no fue lo usual en otros CCD) cuya estructura tenía la particularidad de no contar con rejas que los separaran claramente, generando entonces ambigüedades y confusiones. Estas zonas grises se reforzaban en aquellos casos en que las prisioneras realizaban trabajos para los represores en las oficinas del Staff, Ministaff u otras, o cuando los victimarios festejaban sus cumpleaños con sándwiches de miga y les hacían regalos, o las llevaban a cenar afuera, a bailar o a pasar el día a una quinta con pileta y guitarreada; cuando ellos les confesaban algo personal y cuando les facilitaban hablar por teléfono con sus familiares e incluso las llevaban a visitarlos y a veces se quedaban, compartían comidas y charlas con sus padres. La vida de los represores transcurría día y noche dentro de la ESMA y no podían compartir esta experiencia con su familia, de modo que lo hacían con algunos detenidos y este trato diario limaba ciertos prejuicios que tenían sobre las guerrilleras ("pensaban que nos cagábamos en la familia, en la patria y que no creíamos en Dios", 180) dando lugar a otro tipo de relaciones más complicadas.

Había un doble juego "perverso" de estos represores que pasaban de la tortura y el asesinato a una suerte de protección de sus víctimas, eran sus tutores, las adoptaban. Por un lado, les imponían un modelo de mujer —muy distante del 
estereotipo de la guerrillera masculinizada $-9{ }^{9}$ que debía arreglarse, maquillarse, vestirse bien y emperifollarse para mostrar síntomas de "recuperación" (lo que era una posibilidad para un número muy reducido de prisioneras, solo aquellas elegidas para trabajar podían aspirar a salir con vida de allí). Pero, por otro lado, hay cierto asombro y respeto hacia estas mujeres guerrilleras por sus conocimientos, preparación y destrezas intelectuales (de allí que las convertían en trabajadoras esclavas que traducían textos a diversos idiomas, que escribían artículos, falsificaban documentos, desgrababan conversaciones, ordenaban archivos, etc.). ${ }^{10}$ Descubrían en ellas otro tipo de modelo femenino, digno de admiración. Ante la sugerencia de Munú al Tigre Acosta de que ellos sí podían volver a sus casas con sus familias durante la noche en lugar de quedarse en la ESMA, este le responde

ustedes son las culpables de que nosotros no nos queramos ir a nuestras casas $[\ldots]$ ¡Con ustedes se puede hablar de cine, de teatro, se puede hablar de cualquier tema... Se puede hablar de política, saben criar hijos, saben tocar la guitarra, saben agarrar un arma! ¡Saben hacer todo! [...] ¡son las mujeres que nosotros creíamos que solo existían en las novelas o en las películas, y esto ha destruido a nuestras familias! Porque... ¡ahora qué hacemos con las mujeres que tenemos en nuestras casas!" (165-166). ${ }^{11}$

${ }^{9}$ Uno de los Verdes (cumplían tareas de vigilancia y eran alumnos de la ESMA, muy jóvenes, en general humildes y provincianos) les dicen "A nosotros, antes de venir acá nos hacen un lavado de cerebro. Nos dicen que ustedes son todos terroristas y que no les importa la familia, la de ustedes ni la de nadie, que lo único que quieren es destruir todo y matar gente y que ponen bombas en todos lados" (204)

${ }^{10}$ Confrontar las siguientes citas: "Teníamos, según sus creencias, determinada contracción al trabajo que ellos valoraban", "había un reconocimiento del nivel político" (150)

${ }^{11}$ La descripción que hace Mirta Clara del estereotipo femenino dentro de la cárcel difiere en parte de aquel que circulaba en el centro clandestino de la ESMA, ya que no se interesaban mucho por las mujeres, querían agarrar a sus maridos, ellas eran encuadradas en el modelo de "tradición, familia y propiedad", eran como sus madres, esposas o amantes pero más peligrosas porque militaban, solían colocarlas como apéndices de sus compañeros, eran las "hincha pelotas" como todas las mujeres (293-294). 
Compartían un universo que iba mucho más allá de la relación esperable entre un victimario y su víctima, lo que en ocasiones entorpecía el cabal reconocimiento del rol de victimarios, las llenaba de culpas y confusiones que luego irían aclarando y visualizando a través de la terapia. ${ }^{12}$ Uno de los aportes fundamentales de estos testimonios consiste en explorar ese escenario de ambivalencia, confusión, de sometimiento y regalías, que se configuró en la ESMA entre los represores y sus víctimas.

No obstante, el dispositivo del género no invade el libro entero ni ocupa su centro, sino que despunta y señala cuestiones claves sin entrar en un análisis pormenorizado, apenas se mencionan algunos de los tabúes como los casos de las "detenidas que se enamoraron de sus torturadores" (94), aunque sin detenerse demasiado en cada caso $(147-148,192) .{ }^{13}$ En cambio, será Putas y guerrilleras (2014) de Miriam Lewin y Olga Wornat el texto que se despliega decididamente en torno al eje del género y que podemos analizar para explorar un tercer momento en que los testimonios de matriz humanitaria terminan por encontrarse con las perspectivas de género.

\section{3. El terrorismo sexual en Putas y guerrilleras}

${ }^{12}$ Confrontar la siguiente cita de Munú : "Y además creo que es sano aceptarlo [la circulación del afecto] [...] Cuando uno está durante meses viendo todos los días a las mismas persona, cuando la vida depende de ellos y uno siente, equivocadamente o no, que en la cotidianidad se van generando espacios, resquicios por donde influir y conseguir alguna gracia para sí y para otros compañeros, cuando el que te torturó y te sigue manteniendo sometida es la misma persona que te permite comunicarte con tu familia para llevarle un poco de tranquilidad [...] cuando pensás que te podría haber destruido más y no lo hizo... nada es muy fácil de explicar, nada es absolutamente lineal, los grises existen y son de una profundidad abismal. A mí me llevó años poder destrabar este nudo [...] quizás haya sensaciones contradictorias que nos acompañarán de por vida" (199).

${ }^{13}$ Resulta interesante el argumento de Munú, quien deposita en la mujer la posibilidad de decisión, frente a una violación: "Yo pensaba que era violación, pero no sabía cómo funcionaba el hecho para ella. Quizás lo hacía como un medio para intentar sobrevivir" (193). En Putas y guerrilleras se critica este tipo de razonamiento considerando que, al no existir la libertad de decisión, siempre estamos frente a una violación. 
Con Putas y guerrilleras publicado en 2014 estamos en otro contexto en el que los movimientos feministas han adquirido una notable presencia pública en Argentina, han penetrado en la opinión pública forjando una conciencia sobre las cuestiones de género y se proyectan con fuerza hacia el futuro. Por un lado, en este avance comienza a reconocerse cada vez más la violencia doméstica padecida por las mujeres —que confluirá en el surgimiento de Ni Una Menos en 2015 para protestar por los femicidios - y a denunciarse las redes de trata de personas. Por otro lado, se fueron promoviendo demandas por nuevos derechos y leyes como la aprobación, fundamentalmente, del matrimonio igualitario que permite el casamiento de personas del mismo sexo (2010) y la ley de identidad de género (2011) que posibilita tener la identidad civil de acuerdo con la identificación sexogenérica subjetiva, entre otros adelantos (Barrancos). Para graficarlo de un modo sucinto: las mujeres han salido a la calle haciéndose visibles en diversas manifestaciones como las marchas del $8 M$ y de $N i$ Una Menos, o las campañas por el Derecho al Aborto Legal, Seguro y Gratuito, ${ }^{14}$ creando una expresión multitudinaria que desbordó los límites nacionales y se extendió globalmente, una "marea" verde imparable.

También se advierten cambios y avances en el campo de los juicios de lesa humanidad que paulatinamente se van a focalizar en los crímenes sexuales, tal como se advierte en Putas y guerrilleras. En este extenso volumen, Miriam Lewin y Olga Wornat recogen y reelaboran una gran cantidad de testimonios que desde diversos ángulos se detienen en lo que ellas califican ya decididamente bajo el término "terrorismo sexual", una práctica sistemática implementada por la dictadura y no una desviaciones individual, cuya intención consistió en incluir dentro del terrorismo de Estado la violencia sexual como instrumento para

${ }^{14}$ La Ley de Interrupción Voluntaria del Embarazo (IVE) No 27.610 de Argentina fue sancionada por el Congreso Nacional el 30 de diciembre de 2020 y promulgada el 14 de enero de 2021. Establece el derecho al aborto en todos los casos hasta la semana catorce inclusive, manteniendo la vigencia del derecho al aborto en casos de violación y riesgo para la vida o salud de la madre, sin límite de tiempo. 
aterrorizar, someter, disciplinar a las prisioneras y prisioneros. ${ }^{15}$ En la ESMA circulaba la información de que el Tigre Acosta había dado la orden expresa a los oficiales de que tuvieran relaciones sexuales con las detenidas (243).

La estructura de cada uno de los relatos de este volumen articula un testimonio sobre violencia sexual con el juicio vinculado al mismo y con la ley que en ese momento es utilizada. Esta arquitectura deja en claro la estrecha relación entre el testimonio volcado en un texto y el testimonio declarado ante la justicia. Ambos siguen un recorrido pautado por el paulatino avance de la ley en el reconocimiento del delito sexual como un caso particular de violencia. Ello explica la elección de una tercera persona que narra cada caso, que selecciona las citas de fragmentos de las y los testigos necesarios para sostener los razonamientos, y que ordena los argumentos de un modo impecable. No es solo una recopilación de testimonios, entrevistas y declaraciones sino un estado de la cuestión y un análisis sobre el desenvolvimiento del terrorismo sexual durante y alrededor de la dictadura argentina.

Salvo en las dos introducciones que ambas autoras escriben separadamente, luego no hay una distinción de sus voces en el interior del texto. Sin embargo, a diferencia de Ese infierno..., cuyas autoras exponen sus testimonios desde sus propias experiencias circunscriptas al interior de la ESMA, en Putas y guerrilleras es posible advertir la combinación de una mirada de adentro y otra desde afuera. Mientras Miriam Lewin estuvo secuestrada en los CCD "Virrey Cevallos" de la Fuerza Aérea y en la ESMA, Olga Wornat, si bien fue militante de Montoneros, no estuvo detenida ni sufrió las vejaciones de los represores (por ello se hubo sentida excluida del "ghetto de los sobrevivientes" 44). Esta doble mirada, que va más allá de la voz de las "hermanas de campo", auspicia una notable y múltiple apertura del texto.

\footnotetext{
${ }^{15}$ María Sonderéguer y Violeta Correa explican "este concepto de terrorismo sexual, desarrollado por Carole Sheffield (1997). La autora sugiere que hay un tratamiento distinto del terrorismo político y del terrorismo sexual por parte de la sociedad. En el terrorismo político se distingue terrorista de víctimas [...] pero en el terrorismo sexual se excusa al victimario y se culpabiliza siempre a la víctima" (298).
} 
No se centra en un solo campo, sino que recorre varios espacios de detención ( $\mathrm{CCD}$, comisarías e incluso un buque A.R.A. Muratore) ubicados en diversos puntos del mapa argentino desde grandes ciudades a reducidos vecindarios. Las experiencias difieren en cuanto a los territorios y localidades en las que se sitúan, a la clase social de la víctima, a los contextos culturales, las costumbre y tradiciones de cada comarca. En algunas ocasiones se trata de pequeñas ciudades conservadoras, donde todos se conocen y las víctimas se resisten a declarar ante el temor del rechazo social de sus vecinos. En otros casos, como en Bahía Blanca, estamos ante un sitio con una mayoría de familias militares en la población que se reúnen en barrios propios y conservan sus costumbres tradicionales (405). No solo se exponen las prácticas del terrorismo estatal a través de los represores en los CCD, también se exploran los sectores e instituciones cómplices y colaboradoras con la dictadura, tales como el periódico La Nueva Provincia de Bahía Blanca que se constituyó en un bastión del llamado "Proceso de Reorganización Nacional" a través de la arenga de sus editoriales y de la publicación de falsos enfrentamientos con guerrilleros. O la cooperación del sector empresarial como el caso del Ingenio Ledesma, situado en Jujuy, de la familia Blaquier que ofreció los vehículos de la empresa durante el "Apagón" de luz iniciado la noche del 21 de julio de 1976 facilitando una redada en el pueblo de Calilegua y alrededores que culminó con el secuestro de unas cuatrocientas personas (479-490). A las mujeres y varones víctimas de violaciones se suman las travestis (491-504) y las prostitutas (505-527) que suelen constituir voces más ausentes en las memorias de la represión y permiten iluminar otros modos de injerencia del género en el terrorismo sexual.

El modus operandi dependía de cada CCD ya que en algunos solo se permitían vejaciones sexuales en el momento de la tortura a modo de "iniciación" y otros alentaban las violaciones permanentes y los vínculos más duraderos, en algunos casos la violencia extrema dominaba la escena con métodos y prácticas brutales y abyectas, mientras en otros existía una previa seducción no exenta de una cuota de refinada perversión, alternando un trato "caliente y frío" que iba, por 
ejemplo, de la cena en un restaurante frecuentado por la farándula al sótano de la ESMA. Los manoseos, las miradas sobre el cuerpo desnudo en las duchas, la inexistencia de intimidad respecto a la satisfacción de necesidades fisiológicas en los baños, los insultos soeces y los comentarios de carácter íntimo, las violaciones singulares o grupales de toda índole y calibre, la organización de fiestas sexuales, la picana en los genitales o el coito eléctrico, provocaron no solo una herida psíquica de difícil cura sino también graves lesiones en los órganos sexuales internos y externos de las mujeres y de los hombres. Los embarazos producto de las violaciones en algunos casos y seguidos de abortos obligados por los propios represores o encarados por las víctimas, o aquellos embarazos dudosos en los que la mujer no sabía quién era el padre, si su pareja o el represor, forman todo otro capítulo en la lista de trágicas consecuencias de los crímenes sexuales. A ello se suman las mujeres embarazadas que eran detenidas y que, en varios centros, como ya dijimos, eran cuidadas hasta el momento del parto para luego asesinarlas y apropiarse de sus hijos.

La función de denuncia que todo testimonio supone también es sobrepasada en este volumen por las perspectivas analíticas abocadas a discutir, desde el psicoanálisis, la historia, la sociología, el periodismo, la crítica literaria, etc., el complejo entramado del terrorismo sexual vinculado incluso a otros casos como los de la Alemania del nazismo, o los más recientes de la ex Yugoslavia o Ruanda. Encontramos, además, una subjetivación de cada víctima en tanto se recuperan núcleos centrales de su biografía — la familia de la que proviene, su educación, casamiento o parejas, sus propios hijos, etc.- y una politización ya que se repone su militancia frente al anonimato y despolitización predominantes en el Nunca Más.

Este texto marca enfáticamente la necesidad de un cambio radical de mirada, de un giro en las perspectivas sobre la historia reciente que no solo advierta y denuncie los crímenes de índole sexual cometidos e inste a que las víctimas declaren en los juicios, sino que atañe a cada ciudadana/o en el modo de comprender y evaluar lo acontecido a las mujeres en los Centros clandestinos de detención, en especial los vínculos con los represores que constituyen un tabú difícil 
de desanudar. Junto con el cambio en las leyes y en los juicios, se hace indispensable un giro a nivel cultural que pasa necesariamente por los juicios evaluativos de cada una/o.

Esta transformación de la mirada protagonizada por el empleo del dispositivo del género ocupa el centro de las introducciones de Miriam Lewin y Olga Wornat. Se trata de un relato de aprendizaje que se inicia con una ceguera sobre ciertas relaciones más o menos duraderas, y que en algunos casos pervivieron más allá del campo, entre las detenidas y los represores que ellas habían calificado como "vínculos amorosos", "enamoramientos", "amores perversos" o "malos amores". ${ }^{16}$ En cambio, ahora las perspectivas sobre género les permiten comprender las redes del poder terrorista que sometían a las prisioneras a todo tipo de vejaciones. En esta línea la escena en el almuerzo con Mirtha Legrand resulta ilustrativa ya que cuando Miriam Lewin asistió a la misma en el año 2004 no supo responder correctamente a la insinuación de la conductora sobre presuntas relaciones sexuales con los represores que les permitirían haber sobrevivido. Recordemos que ese año del 2004 coincide con la escritura de la segunda versión de Ese infierno... que analizamos como una instancia inicial y precaria donde se estaba gestando esta mirada desde el género. En cambio, al volver sobre ese almuerzo desde el presente ahora sí le hubiera respondido con claridad afirmando la falta de libertad para resistirse en ese estado de sometimiento y el derecho al uso del cuerpo para salvar la vida. "No puedo culpar a Mirtha sobre todo porque, en las antípodas en cuanto a ideología, en los años del desastre yo tenía los mismos prejuicios, idéntica falta de comprensión de las relaciones de poder y levanté mi dedo acusador contra mis pares en desgracia. Y no estaba sola en esa ceguera", observa Miriam Lewin (15-22). Por su parte, Olga Wornat reconoce "Mientras

${ }^{16}$ Ciertos vínculos se convirtieron en íconos, como el de Anita Dvatman (alias Barbarella) cuyo matrimonio con el represor Jorge Radice (Ruger), con quien tuvo dos hijos, perduró más allá de la estancia en la ESMA, y el de Mercedes Inés Carazo (Lucy) y el represor Antonio Pernías (Rata) que ocupó un lugar importante en varios textos literarios como Recuerdo de la muerte de Miguel Bonasso (1984), El fin de la historia de Liliana Heker (1996) y Noche De Lobos (2011) de Abel Posse. 
pasaron los años y yo me comprometía más y más en estas historias, dejé de creer que estas relaciones eran "amores perversos" o un "síndrome de Estocolmo", para asumir con total convicción que son crímenes aberrantes, delitos de lesa humanidad, y que había estado equivocada durante largos años" (74).

Estas malinterpretaciones fueron producto de la invisibilización del sistema de dominio al que estaban sometidas, así como de la introyección de imaginarios, modelos, roles, costumbres o conductas características del patriarcado que permeaban los juicios de valor no solo de los represores, sino también de las agrupaciones guerrilleras, de los organismos de derechos humanos, de la sociedad y de las mismas víctimas. Comprender el terrorismo sexual conlleva entender las vejaciones y violaciones a las mujeres como armas de guerra, empleadas por los represores, de diverso uso y alcance: el cuerpo femenino se convierte en la arena donde se dirime quién es el vencedor y quién el vencido, en un trofeo o botín de guerra que incluso puede ofrecerse a otro prisionero como premio a sus méritos en la colaboración. Ante la violación se quiebra la imagen del esposo o compañero como macho protector y se despierta la culpa en la mujer vejada. Se trata de un castigo hacia las mujeres guerrilleras por haber abandonado los moldes de la esposa y madre adjudicados por el patriarcado, es un modo de sometimiento, dominio e intento de reencauzarlas, así como una prueba de "recuperación" en aquellas que aceptan vínculos con los represores, es también un modo de sembrar miedo indiscriminadamente (187-213). Las "viudas ilustres" -Jorgelina Ramus, Norma Arrostito, Norma Susana Burgos, Sara Osatinsky, entre otras- conformaban dentro de la ESMA el "botín de guerra", eran mujeres insignes que servían para exhibir el poder de la Marina frente a las demás fuerzas represivas y eran una ofrenda a Massera (244).

La dictadura reforzó el mandato patriarcal, como afirma Paola Martínez (2017), provocando una resignificación de la masculinidad y de la feminidad. Mientras la masculinidad estuvo representada por el poder absoluto de los torturadores sobre los cuerpos de las y los detenidos, la feminidad fue asociada con la pasividad tanto de mujeres como de hombres. Se trataba de encarrilar la 
masculinización de las guerrilleras feminizándolas y de feminizar a los varones para someterlos y debilitarlos (Martínez ). El represor asumía, en ciertos casos, el rol del custodio de la moral social que corregiría los desvíos inmorales y las rebeldías provocadas por las guerrilleras dentro de la familia modelo basada en la tradición "Dios, Patria, Hogar" (Martínez).

Los estereotipos que circulaban entre los represores se entrecruzaban con otras dimensiones del universo patriarcal. Así en el CCD La Cueva de Mar del Plata encontramos tres tipos femeninos que padecieron violaciones por parte de Gregorio Molina: Marta García de Candeloro respondía al perfil de "la señora", era universitaria, esposa de un abogado, una "dama de aspecto distinguido" que despertó el resentimiento de clase en el violador quien manifiesta los motivos de la agresión sexual "Porque vos sos una señora y afuera no me darías pelota". En cambio, Mercedes Lohn, una mujer muy humilde, empleada doméstica, que además de las violaciones era obligada a limpiar el lugar, ocupaba el lugar de "la sirvienta". A su vez, Mirta, de 18 años, que estaba siempre arreglada y con las uñas pintadas, calzaba en el modelo de "la prostituta" (133-156). Otro de los imaginarios femeninos, lejos de demonizarlas como guerrilleras o de visualizarlas desde parámetros sociales, las recolocaba como "apéndice del hombre" reduciéndolas a un rol subalterno que facilitaba su liberación a los pocos días ya que sus maridos eran los buscados (208).

Varios imaginarios patriarcales sostuvieron ciertas sentencias condenatorias esgrimidas por los miembros de Montoneros, quienes incluso podían fusilarlas por traidoras. También los sobrevivientes (y los militantes de derechos humanos) ponían bajo sospecha a estas mujeres y les exigían nuevas pruebas de lealtad cuando llegaban al exilio. Estas condenas terminaban por formar parte de la mirada de las víctimas sobre ellas mismas. La exigencia de resistencia y heroicidad de la mujer ante la agresión sexual supone que solo hay violación cuando la mujer rechazó enfáticamente al varón, e implica el mandato de poner en riesgo su vida para salvar su vagina. Si no hay resistencia, no hay violación. La alternativa excluyente entre "mártires o prostitutas", que antepone el sacrificio de la propia 
vida en aras de una pureza virginal antes de haberse entregado al enemigo, da lugar a los tópicos de "traidora", "colaboradora", "amante de los milicos" o "puta", cuando en realidad eran "esclavas sexuales".

El peso de estos conceptos generó una alta dosis del sentido de culpabilidad, de contaminación, de abyección en las mujeres violadas, que aun fue más fuerte cuando la violación estuvo precedida por una instancia de seducción por parte del represor y de variadas formas de ayuda que ellos brindaban a sus víctimas como permitirles hablar o visitar a sus familiares, asegurarles protección dentro del CCD, augurarles una sobrevida, conducirlas como tutores en el proceso de recuperación, entre otras. Lo que daba lugar a percibirlos como "salvadores" y deberles un "agradecimiento" que les resultó difícil de desandar y les impidió declarar en su contra, que precisó de terapias para recolocarlos en el lugar de los perpetradores y a ellas como sus víctimas carentes de la necesaria libertad de elección que todo vínculo amoroso supone, para advertir las perversas coacciones a las que fueron sometidas, para saber que no mantenían relaciones sexuales, sino que eran abusadas.

Algunas intentaron modos de evadir el acoso cubriendo su cuerpo de ropas anchas, negando su feminidad y sexualidad como Elisa Tokar (240), otras como Inés Cobo, violada por el Tigre Acosta, terminó enloqueciendo (96) y algunas como Laura Di Doménico quien deseaba ser religiosa y vestía ropas sencillas se transformó en una mujer sensual con uñas pintadas y remeras ajustadas (86).

La construcción de una testigo que se anima a declarar aparece como un trayecto surcado por varios obstáculos: dejar de sentir vergüenza y pudor en especial ante sus familiares más cercanos, que en muchos casos desconocían que habían sido violadas, superar la culpa y los estigmas condenatorios y degradantes, deshacerse del "agradecimiento" hacia el represor, atravesar terapias que lograran invertir los roles y recolocar a la mujer como víctima ante el perpetrador victimario, enfrentar las amenazas y los peligros que suponía el acto de prestar testimonio ante un tribunal con capacidad para condenar. Todo lo cual implicaba advertir que el 
terrorismo sexual era un modo particular de dominio, sometimiento y guerra atravesado por el género.

Respecto a los juicios también encontramos un relato de progreso (que no obvia los retrasos, los inconvenientes y los obstáculos de la justicia) hacia el reconocimiento de las violaciones y abusos como delitos sexuales que se encuadran en los crímenes de lesa humanidad. El juicio a Gregorio Molina llevado a cabo en 2010 por el Tribunal Oral Federal de Mar del Plata constituye un hito clave en tanto fue la primera vez en que hubo una condena a prisión perpetua por un "delito sexual como crimen de lesa humanidad" (156). En 2011 este fallo fue reconocido internacionalmente por fomentar la equidad de género con el premio Mallete (332).

Este juicio fue, sin embargo, el momento culminante de todo un proceso más extenso. Recordemos que en principio las violaciones no eran consideradas en su especificidad e independencia, sino como "una forma más de tormentos", equiparable a otras. Lo que no respondía a la realidad. Asimismo, comenzaron a visualizarse como una acción sistemática y no como hechos aislados, encuadrándose en el despliegue de un "terrorismo sexual" por parte del Estado. Varios fueron los cambios que desde la justicia se debieron encarar. Las violaciones no tenían el carácter de hecho demostrable ya que no estaba la posibilidad de recolectar semen, pelos, piel, etc., y resultaba muy difícil contar con testigos debido al paso del tiempo y a que en su momento los y las detenidos/as estaban tabicados y no podían ver. Por ello fue suficiente con reconocer la coherencia de los testimonios y su reiteración en diferentes oportunidades que mostraran las mismas prácticas. La "autoría" fue objeto de revisión dejándose de lado la autoría "de propia mano" para contemplar como autores a todos aquellos que "dominan la configuración de la escena de un modo significativo, más allá de que fueran ellos los que cometieran de mano propia el delito" (348). De la primera consideración por parte del Código Penal de "delito contra la honestidad" se pasó a "delito contra la integridad sexual" y finalmente a "delito contra la libertad sexual". Ello implicó dejar atrás la caracterización de la violación como un "delito de instancia privada" que requería la iniciativa y autorización de la víctima para acusar. Por otro lado, 
como muchas mujeres se resistían a declarar por pudor o temor, y dado el riesgo de revictimizarlas en los juicios, se elaboró una guía para que los funcionarios judiciales fueran orientados en la tarea de escuchar y tratar a las víctimas con respeto y cuidado. Los dilemas pusieron en tensión el riesgo de volver a traumatizar a la víctima con el efecto sanador que suele tener el acto de testimoniar, pero también tensionaron la voluntad de respetar a la víctima con la necesidad de ir más allá de los casos particulares. La sociedad fue acompañando estos cambios en el modo de juzgar a estas mujeres.

En estos avances fueron de capital importancia las consideraciones elaboradas por los Tribunales penales internacionales de la ex Yugoslavia (1993) y de Ruanda (1994) donde la violencia sexual fue tipificada como delito de lesa humanidad (y por ello imprescriptible) cuando forman parte de un ataque sistemático (329-350). Finalmente, las autoras consideran que "cuando se da una relación sexual en un contexto de secuestro, en un centro clandestino de detención, nunca podemos aceptar que hubo consentimiento, porque no existe la posibilidad de consentimiento en un contexto concentracionario" y agregan: "Ni siquiera extinguido el cautiverio físico puede presumirse que la víctima tenga la salud mental, el equilibrio o la fuerza de voluntad que permitiría el libre albedrío (Lewin y Wornat 342; Balardini, Oberlin y Sobredo).

Como venimos percibiendo, este volumen, además de aportar una enorme cantidad de información sobre diversos casos, propone una mirada analítica que recorre diversos aspectos en torno a las tramas del terrorismo sexual, recurriendo al aporte de varias disciplinas, algunas ya presentes como el derecho y el psicoanálisis. Se discute, por ejemplo, el concepto del "síndrome de Estocolmo" entendido como un trastorno emocional caracterizado por la justificación moral y el sentimiento de gratitud de un sujeto hacia otro de quien forzosa o patológicamente dependen sus posibilidades reales o imaginarias de supervivencia. Esta perspectiva no alcanzaría para comprender el caso de tantas mujeres que no se identificaban amigablemente con sus represores, sino que estaban sometidas y procuraban sobrevivir, acusándolos una vez fuera del campo. Estas miradas que 
focalizan en las actitudes de las víctimas terminan por invisibilizar las estructuras de dominación subyacentes (335-336). En otra oportunidad, se recuperan argumentos de Rita Segato para comprender ciertos vínculos entre las violaciones y la religiosidad que permiten visualizar al violador como un moralista extremo que procura corregir los desvíos femeninos (395). El modo elegido para escribir sobre los crímenes sexuales también ocupa uno de los capítulos. Aquellas escrituras que muestran sin tapujos las crudezas han sido criticadas por desviarse del buen gusto, herir susceptibilidades, revictimizar a las víctimas, caer en el exhibicionismo, suscitar la provocación y la pornografía, apelar a una baja calidad literaria. Frente a estas tesis, las autoras defienden las escrituras que permiten testimoniar los delitos sexuales en su crudeza y sin eufemismos, ni tapujos ni tabúes como una vía para provocar rechazo e indignación. "El derecho de las víctimas de hablar, de plasmar su testimonio, tiene que prevalecer necesariamente sobre la mojigatería, los prejuicios y la consideración de la sensibilidad del lector", sostienen las autoras $(443-451) .^{17}$

Putas y guerrilleras aparece como un hito culminante en este recorrido que he trazado, un punto de reunión que convoca muy diversos testimonios sobre violencia sexual con un notable afán, logrado ciertamente, de una plural exhaustividad. Este notable corpus testimonial está acompañado, además, por una dimensión analítica que indaga en la trama del terrorismo sexual desde diversos ángulos. Constituye una suerte de punto de arribo. Esta certeza me ha llevado a elegir el siguiente volumen - Escritos desobedientes - que, escrito por hijas e hijos de represores, permite atender a la emergencia de una nueva voz tanto en los testimonios volcados en textos y esgrimidos en los juicios como en la militancia.

${ }^{17}$ Sin intención de agotar, podemos agregar dentro del corpus testimonial escrito por mujeres los siguientes libros, entre otros: un conjunto de testimonios en el sitio de Memoria Abierta; Sueños sobrevivientes de una montonera (2000) de Susana Jorgelina Ramus; Nosotras. Las presas políticas (2006) de Viviana Beguán, Alicia Kozameh y Silvia Echarte; Memorias de una presa politica (2006) de Graciela Lo Prete; Memoria de mujeres: relatos de militantes, ex presas políticas, familiares de desaparecidos y exiliadas (2011) de María Rosa Gómez; "Y nadie quería saber". Relatos sobre violencia contra las mujeres en el terrorismo de Estado en Argentina (2012) por Memoria Abierta; El silencio. Postales de la Perla (2017) de Ana Iliovich; etc. 


\section{El discurso feminista}

Un doble movimiento va a cruzar aún más a la narrativa humanitaria con la militancia feminista. Por un lado y como ya adelantamos, el notable avance y expansión de las organizaciones feministas, las marchas del $8 M$ y de Ni Una Menos, las campañas por el Derecho al Aborto Legal, Seguro y Gratuito, es decir esa "marea verde" que recorrió varios puntos del planeta penetrando en la opinión pública, modificando leyes, transformando la educación, permeando la política.

Por el otro, el impulso de los derechos humanos que los colocó en el centro de la reapertura democrática dando lugar a las políticas de la memoria, verdad y justicia, poco a poco se va abriendo hacia el reclamo de otro tipo de violaciones de derechos humanos ocasionados por el gatillo fácil, el narcotráfico, las migraciones, y varias enfocadas en el género como los femicidios, la trata de personas, etc. Gabriel Gatti observa la expansión y diversificación de la noción de víctima como un fenómeno actual en su libro colectivo Un mundo de víctimas (2017). Desde el lugar hegemónico alcanzado por los juicios de lesa humanidad, la noción de víctima ha invadido otros espacios, ha ampliado su espectro y se ha extendido a la conculcación de otros derechos humanos, como las víctimas de violencia de género, de accidentes de tráfico, de los efectos de contaminación, de robos de bebés, entre tantas otras. Se ha abierto para alojar al ciudadano ordinario, dejando de ser el "otro" social, e incluso se ha globalizado: estamos ante el "ciudadano víctima". Se ha vuelto "central, masiva, numerosa". Organizada en colectivos y asociaciones, recibe el apoyo y la colaboración de diversas instituciones y profesionales (asistenciales, jurídico legales, asociativas, administrativas, etc.) para interpelar al Estado con sus demandas de reparación, promover normativas y leyes, y fomentar una política pública de reconocimiento y visibilidad, tal como ha acontecido con las demandas del feminismo y de diversas agrupaciones de mujeres que luchan por los femicidios, el consumo de drogas como las "Madres del Paco", las "Madres 
Víctimas de Trata", la "Fundación María De Los Ángeles, Por La Lucha Contra La Trata De Personas", por citar apenas algunas.

Para ilustrar un paso más en esta confluencia entre las luchas por la memoria en clave humanitaria y el feminismo, resulta pertinente abordar la creación en 2017 del colectivo Historias Desobedientes: Familiares de genocidas por la Memoria, la Verdad y la Justicia, que constituye una nueva voz, la de aquellas/os hijas/os de padres represores que sin embargo se distancian de ellos y los acusan. Este cruce es visible, en primer lugar, en la aparición pública de la agrupación ya que salen por primera vez con banderas propias el 3 de junio de 2017 en la movilización organizada por Ni Una Menos. Este bautismo de una agrupación de derechos humanos vinculada a las luchas por la memoria en un espacio de militancia del feminismo es todo un síntoma del cambio de contexto. En segundo lugar, la publicación de Escritos desobedientes (2018) articula una mirada feminista en sus testimonios. De este modo la perspectiva de género va a permear tanto las prácticas militantes como los relatos donde examinan sus infancias en hogares militares, doblemente sometidas a la violencia patriarcal del padre y del militar.

Escritos desobedientes se divide en dos partes —más allá del Manifiesto que abre y del Posfacio que cierra el volumen-. La primera de ellas, "Historias de vida", incluye los relatos en primera persona bajo subtítulos con los nombres y apellidos de quien escribe: esta preeminencia del "yo" promete una enunciación desde el interior privadísimo de la escena familiar que saque a la luz y revele las experiencias de una infancia con un padre, abuelo o familiar represor -cuyo rostro ensaya variantes entre el buen padre, el padre violento en casa o el monstruo represor afuera, entre otros-. En cambio, los "Relatos desobedientes", la segunda parte, escritos desde un yo comunitario, representativo de la agrupación y de carácter institucional, recorren desde sus mismos títulos los manifiestos, las decisiones y las prácticas públicas y políticas de este organismo creado en 2017. Pero no hay hiato entre ambas partes ya que, como sabemos, "lo personal es político" y aún más en el espacio de la militancia por parte de varios organismos de derechos humanos en Argentina, basados en el vínculo familiar con las víctimas del 
terrorismo estatal. Incluso, la primera parte aparece como garantía y sostén de la segunda: "el repudio cobra mayor sentido, mayor fuerza, como genuina posición ética, a partir del lazo del afecto" (53), afirma Bibiana Reibaldi y con ello destaca el centro del conflicto que tensa el amor al padre represor con el rechazo a su conducta, contraponiendo el afecto a la ética (Basile "Escritos desobedientes").

Uno de los frentes de pelea que afrontan - tanto hacia el espacio militar como hacia la sociedad - es la declarada política feminista que lleva, como ya adelantamos, a muchas hijas a la marcha de Ni Una Menos en 2017, en la que se presentan a la sociedad. "No es casual que Historias desobedientes esté conformado por una mayoría de mujeres" — sostiene Carolina Bartalini (Bartalini 18) — y varios de estos relatos están en clave feminista y de género. Desde allí van a interrogar el "machismo" y los valores "patriarcales" sostenidos por sus padres. La predilección por los hijos varones en la "familia militar" se vuelve punto de arranque en la historia de vida de Lorena Milena, ya que nació mujer "cuando esperaban un varón [...] nunca me lo perdonó" (106). "Casarse con un milico", "tener hijos" o convertirse en "maestra" e ir a enseñar a "alguna provincia" son los destinos que le traza su padre (107). En el caso de Liliana Furió la rebelión contra su progenitor adviene al mismo tiempo en que se divorcia y se vuelve lesbiana: la búsqueda de su identidad la conduce por una doble desobediencia a la ley del padre y a la ley del género. En esta clave filmó su documental Tango Queerido, que se inserta en el movimiento internacional del tango queer, que procura deconstruir el machismo tradicional del tango y reinterpretar su oculta huella homosexual. Por su parte, el relato de Lizi Raggio también está en clave femenina: escribe, como parte de un proyecto narrativo sobre historias de mujeres, un texto sobre su familia centrado en la figura de su tía abuela Josefina, quien como una heroína le solicita a la protagonista limpiar la estirpe manchada (93-97). La desobediencia, además, quiebra la condición sumisa de la mujer, la convierte a los ojos de los padres en la "oveja negra": "no somos quienes ellos querían que fuéramos", sostiene Carolina Bartalini (18). El "machismo" presente en la familia militar suele ser una nota 
constante en estas historias de vida, que luego impulsa la militancia feminista de la agrupación Historias desobedientes.

Desde luego que se podría haber elegido algún otro ejemplo de los abundantes que hay para ilustrar esta confluencia entre derechos humanos y feminismo, como por ejemplo Aparecida (publicado en 2015) de Marta Dillon, donde se encuentra una apuesta a las políticas de género en las leyes de matrimonio igualitario (2010) que le permiten a la autora casarse con Albertina Carri, o las reiteradas apariciones de organismos de derechos humanos como H.I.J.O.S. en las marchas feministas —así, en el 8M de la ciudad de Rosario del 2018 irrumpió una columna cuya bandera atravesaba la letra "O" con la "A" de H.I.J.A.S. La elección del colectivo Historias Desobedientes, sin embargo, parece augurarnos la apertura de una mirada feminista, que recién comienza, hacia el interior del universo de los represores y de la familia militar ejercida por sus propias hijas/os desde las luchas por la memoria, verdad y justicia. ${ }^{18}$

\section{Bibliografía}

Actis, Munú; Cristina Aldini, Liliana Gardella, Miriam Lewin y Elisa Tokar [2001] Ese infierno. Conversaciones de cinco mujeres sobrevivientes de la ESMA. Buenos Aires: Altamira, 2006.

Amado, Ana. La imagen justa. Cine argentino y política (1980-2007). Buenos Aires, Colihue, 2009.

Bacci, Claudia. "El trabajo del tiempo: género y generaciones en algunas escenas testimoniales". En Voces de la violencia: avatares del testimonio en el Cono Sur. La Plata: EDULP, 2020: 122-149.

Balardini, L., A. Oberlin y L. Sobredo. "Violencia de género y abusos sexuales en centros clandestinos de detención. Un aporte a la comprensión de la experiencia argentina". En Centro de Estudios Legales y Sociales (CELS), Hacer justicia: nuevos debates sobre el juzgamiento de

18 Analizo un extenso corpus de textos de hijas/os de represores en "Padres perpetradores. Perspectivas desde los hijos e hijas de represores en Argentina (Basile)". 
crímenes de lesa humanidad en la Argentina. Buenos Aires: Siglo XXI, 2011: 167-226, Recuperado de https:/www.cels.org.ar/web/wp-content/ Barrancos, Dora. "Los caminos del feminismo en la Argentina: historia y Derivas". Las Voces del Fénix, 2014. Recuperado de http://www.vocesenelfenix.com/content/los-caminos-del-feminismo-enla-argentina-historia-y-derivas

Bartalini, C. et al. (eds.). Escritos desobedientes. Historias de hijas, hijos y familiares de genocidas por la memoria, la verdad y la justicia. Ciudad Autónoma de Buenos Aires: Marea, 2018.

Basile, Teresa. Aproximaciones al "testimonio sobre la desaparición de personas" durante la dictadura y la democracia argentinas. Alp: Cuadernos AngersLa Plata, 2 (2), 1998: 45-64. . Reseña del libro Escritos desobedientes. Historias de hijas, hijos y familiares de genocidas por la memoria, la verdad y la justicia de Analía Kalinec (comp.). Aletheia, 9(18), 2019: 1-3. DOI: https://doi.org/10.24215/18533701e017

. "Padres perpetradores. Perspectivas desde los hijos e hijas de represores en Argentina”. Kamchatka. Revista de análisis cultural 15 (Junio 2020): 127-157. DOI: https://doi.org/10.7203/KAM.15.15714

. "Reinstitucionalización del testimonio en América Latina desde la narrativa humanitaria". Aletheia Vol. 11, $\mathrm{n}^{\circ} 21$, segundo semestre de 2020. Universidad Nacional de La Plata. Online.

Crenzel, Emilio. La historia política del Nunca Más: la memoria de las desapariciones en la Argentina, Buenos Aires: Siglo XXI, 2008.

CONADEP. Nunca más: informe final de la Comisión Nacional sobre la Desaparición de Personas. Buenos Aires: EUDEBA, 1984.

Feld, Claudia. "La representación de los desaparecidos en la prensa de la transición: el show del horror", en Crenzel, E. (coord.) Los desaparecidos en la Argentina: memorias, representaciones e ideas: 1983-2008. Buenos Aires: Biblos, 2010: 25-41.

Gatti, Gabriel. Un mundo de víctimas. Barcelona: Anthropos, 2017.

Lewin, Miriam y Olga Wornat. Putas y guerrilleras. Buenos Aires: Planeta, 2018.

Lvovich, Daniel y Bisquert, Jorgelina. La cambiante memoria de la dictadura. Discursos sociales y legitimidad democrática. Biblioteca Nacional / UNGS, Buenos Aires, 2008.

Longoni, Ana. Traiciones. La figura del traidor en los relatos acerca de los sobrevivientes de la represión. Buenos Aires: Norma, 2007.

Martínez, Paola. "Cuerpos y subjetividades en disputa: Experiencias femeninas en los centros clandestinos de detención en Argentina (1976-1983)".

L'Ordinaire des Amériques, 222, 2017: http://journals.openedition.org/orda/3491

Oberti, Alejandra. Las revolucionarias. Militancia, vida cotidiana y afectividad en los setenta. Buenos Aires: EDHASA, 2015.

Salvi, Valentina. De vencedores a víctimas: memorias militares sobre el pasado reciente en la Argentina. Buenos Aires: Biblos, 2012. 
Simón, Paula. "Palabras de mujeres. Los testimonios femeninos sobre la cárcel y el campo de concentración en la última dictadura militar argentina (19832014). Vegueta. Anuario de la Facultad de Geografía e Historia 19, 2019: 457-485.

Sonderéguer, María y Violeta Correa. "Género y violencias en el terrorismo de Estado en Argentina". Género y poder. Violencias de género en contextos de represión política y conflictos armados, María Sonderéguer (comp.). Editorial Universidad Nacional de Quilmes: Bernal, 2012: 289302.

Tarducci, Mónica "Feminismo y derechos humanos en la posdictadura". Latfem, marzo 23, 2020. https://latfem.org/feminismo-y-derechos-humanos-enla-posdictadura/

Trebisacce, Catalina. "Una segunda lectura sobre las feministas de los '70 en Argentina". Conflicto Social, Año 3, No 4, Diciembre 2010. . "Problemas en la reconstrucción de las memorias de mujeres feministas en los agitados años 70". VI Jornadas de Sociología de la UNLP, 2010. http://www.memoria.fahce.unlp.edu.ar/trab_eventos/ev.5111/ev.5111.pdf Trebisacce, Catalina.; Torelli, M. L. "Un aporte para la reconstrucción de las memorias feministas de la primera mitad de la década del setenta, en Argentina. Apuntes para una escucha de las historias que cuenta el archivo personal de Sara Torres". Aletheia, 1(2), 2011. http://www.memoria.fahce.unlp.edu.ar/ art_revistas/pr.4812/pr.4812.pdf. 